\title{
Studies on the stereoselectivity of the $\mathrm{P}_{2}$-purinoceptor on the guinea-pig vas deferens
}

\author{
G. Burnstock, N.J. Cusack* \& L.A. Meldrum
}

Department of Anatomy \& Embryology and Centre for Neuroscience, University College London, Gower Street, London WC1E 6BT and Department of Pharmacology*, Kings College London, London WC2R 2LS

1 ATP, 2-chloro-ATP, 2-methylthio-ATP and their unnatural L-enantiomers, Rp and Sp diastereoisomers of the ATP phosphorothioate analogues, ATP $\alpha$ S and ATP $\beta S$, were tested on the guineapig vas deferens.

2 The 2-substituted analogues of ATP were no more effective than ATP in causing contraction of the vas deferens. However, stereoselectivity was observed with each pair of enantiomers of ATP, 2-chloroATP and 2-methylthio-ATP.

3 No stereoselectivity was observed for the phosphorothioate analogues. Rp- and Sp-ATPBS were more effective than ATP at eliciting contractions of the vas deferens.

4 These results show that unlike the $\mathrm{P}_{2}$-purinoceptor mediating excitatory responses in the guinea-pig bladder, the $\mathrm{P}_{2}$-purinoceptor mediating contraction in the guinea-pig vas deferens displays stereoselectivity.

\section{Introduction}

Adenine nucleotides have potent pharmacological actions on smooth muscle and can induce relaxation of mammalian gut and contraction of mammalian urinary bladder and vasa deferentia (for reviews see Burnstock, 1978; 1981). In the guinea-pig vas deferens, the response to nerve stimulation is biphasic with an initial rapid twitch component followed by a slower secondary tonic component (Ambache \& Zar, 1971). The second, tonic, component seems to be adrenergic as it is mimicked by application of exogenous noradrenaline and abolished by $\alpha_{1}$-adrenoceptor antagonists and by treatment with reserpine (Ambache \& Zar, 1971; Swedin, 1971). The response to exogenous ATP closely mimics the initial, phasic component and is abolished by the photoaffinity analogue of ATP, 3'-arylazidoaminopropionyl-ATP $\left(\mathrm{ANAPP}_{3}\right)$ (Fedan et al., 1981; Sneddon et al., 1982) and also after desensitization by the $P_{2}$-purinoceptor agonist $\alpha, \beta$-methylene-ATP (Meldrum \& Burnstock, 1983). Since both phases of the nerve response are substantially reduced by 6-hydroxydopamine, which selectively destroys adrenergic nerve terminals (Fedan et al., 1981), this has led to the proposal that noradrenaline and ATP are released together as cotransmitters from these sympathetic nerves.
Some 2-substituted analogues of ATP such as 2azido, 2-chloro- and 2-methylthio-ATP are considerably more potent than ATP at inducing relaxation of the guinea-pig taenia coli (Satchell \& Maguire, 1982; Cusack \& Planker, 1979), although they are not more effective than ATP at contracting the guinea-pig bladder (Burnstock et al., 1983). A comparison of the responses induced by pairs of enantiomers of the 2substituted analogues of ATP showed that, while considerable stereoselectivity was exhibited by the inhibitory $\mathbf{P}_{2}$-purinoceptor mediating relaxation of the taenia coli, virtually no stereoselectivity was observed for the excitatory $\mathrm{P}_{2}$-purinoceptor mediating contraction of the bladder (Burnstock et al., 1983). Further studies using the $\mathbf{R p}$ and $\mathrm{Sp}$ diastereoisomers of the phosphorothioate analogues of adenine nucleotides confirmed the stereoselectivity of the inhibitory $\mathrm{P}_{2}$ purinoceptor in the intestine and the lack of stereoselectivity at the excitatory $\mathbf{P}_{2}$-purinoceptor in the bladc'er (Burnstock et al., 1984). In the present study we have used pairs of enantiomers of 2-substituted analogues of ATP and pairs of diastereoisomers of phosphorothioate analogues of ATP to investigate the stereoselectivity at the excitatory $P_{2}$ purinoceptor on the guinea-pig vas deferens. 


\section{Methods}

Albino male guinea-pigs, $200-300 \mathrm{~g}$, were killed by a blow to the head and exsanguinated. The whole vasa deferentia were removed and mounted in $2 \mathrm{ml}$ organ baths with one end of the tissue fixed to a rigid support and the other attached to the transducer. The preparations were suspended in modified Krebs solution of the following ionic composition (mM); $\mathrm{NaCl} 133$, $\mathrm{KCl} 4.7, \mathrm{NaHCO}_{3}$ 16.3, $\mathrm{MgSO}_{4} 0.6, \mathrm{CaCl}_{2} 2.5$ and glucose 7.7. The solution was gassed with $95 \% \mathrm{O}_{2}$, $5 \% \mathrm{CO}_{2}$ and maintained at $36.5 \pm 0.5^{\circ} \mathrm{C}$. The preparations were initially placed under a resting tension of $1 \mathrm{~g}$ and allowed to equilibriate for $1 \mathrm{~h}$. Contractions were measured by a force-displacement transducer (Grass FT03C) and recorded using a Grass polygraph. Owing to the availability of some of the adenine nucleotide analogues, high bath concentrations of some analogues could not be feasibly used to obtain a maximum response. In order to compare the potency of the analogues, the drug-induced contractions were expressed as a percentage of the maximal contraction of the tissue obtained to $120 \mathrm{mM} \mathrm{KCl}$ (Fedan et al., 1982).

\section{Drugs}

Adenosine 5'-triphosphate (ATP) was purchased from Sigma, London. Adenosine 5'-O-(2-thiodiphosphate) (ADPBS) and adenosine 5'-O-thiomonophosphate (AMPS) were purchased from Boehringer Mannheim. 9- $\beta$-L-Ribofuranosyladenine (L-adenosine) synthesized from L-xylose (Acton et al., 1964) was phosphorylated to $9-\beta$-L-ribofuranosyladenine 5 'triphosphate (L-ATP) as described by Holý \& Sorm (1971). 2Chloro-9- $\beta$-L-ribofuranosyladenine (2-chloro-L-adenosine) was synthesized as previously described (Cusack et al., 1979). 2-Methylthioadenosine and 2methylthio-9- $\beta$-L-ribofuranosyladenine (2-methylthio-L-adenosine) were obtained by displacement of chloride from 2-chloro-adenosine (Maguire et al., 1971) and 2-chloro-L-adenosine (Cusack et al., 1979), respectively, with methanethiol. 2-Chloroadenosine 5 '-triphosphate (2-chloro-ATP) and 2-methylthioadenosine 5 '-triphosphate (2-methylthio-ATP) were synthesized by phosphorylation followed by pyrophosphorylation of 2-chloradenosine and 2-methylthioadenosine, respectively (Gough et al., 1973), and 2chloro-9- $\beta$-L-ribofuranosyladenine $\quad 5^{\prime}$-triphosphate (2-chloro-L-ATP) and 2-methylthio-9- $\beta$-L-ribofuranosyladenine 5 '-triphosphate (2-methylthio-L-ATP) were synthesized in an identical manner from 2chloro-L-adenosine and 2-methylthio-L-adenosine. The $\mathbf{R p}$ diastereoisomer of adenosine 5'-O-(2-thiotriphosphate) (ATP $\beta S$ ) was synthesized enzymically from ADP $\beta S$ by phosphorylation with the combination acetate kinase/acetyl phosphate, and any contaminating Sp diastereoisomer was removed by treatment with myosin. The Sp diastereoisomer of ATPBS was synthesized enzymically from ADP $\beta S$ by phosphorylation with the combination pyruvate kinase/ phosphoenol pyruvate and any contaminating $\mathbf{R p}$ diastereoisomer was removed by treatment with hexokinase (Eckstein \& Goody, 1976; Jaffe \& Cohn, 1978). Adenosine 5'-O-(1-thiotriphosphate) (ATP $\alpha$ S) was synthesized chemically by pyrophosphorylation of AMPS, and the $\mathbf{R p}$ and $\mathrm{Sp}$ diastereoisomers obtained were separated by isocratic $\left(0.01 \mathrm{M} \mathrm{KH}_{2} \mathrm{PO}_{4}\right.$, $\left.2 \mathrm{ml} \mathrm{min}^{-1}\right)$ high pressure liquid chromatography on a reverse phase column ( $\mu$ Bondapak C18, Waters Associates) (Eckstein \& Goody, 1976; Cusack \& Hourani, 1982). The purity of the nucleoside triphosphates was checked by high pressure liquid chromatography and stock solutions were assayed by ultraviolet spectroscopy.

\section{Statistical methods}

Results given are expressed as the mean \pm standard error of the mean (s.e.mean).
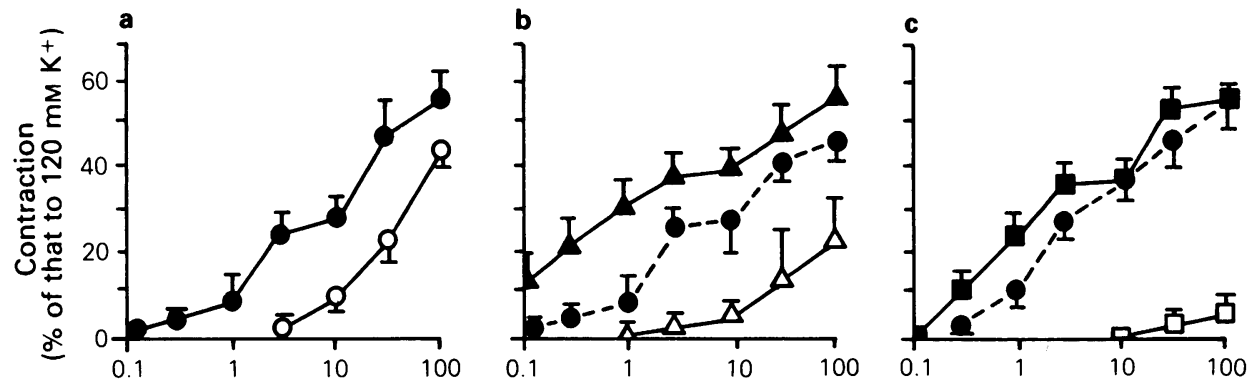

Concentration of nucleotides $(\mu \mathrm{M})$

Figure 1 Concentration-response curves of the guinea-pig vas deferens to the contractions of (a) ATP(O), and L-ATP (O), (b) 2-chloro-ATP ( $\Delta$ ), 2-chloro-L-ATP $(\Delta)$, and ATP (O), (c) 2-methylthio-ATP ( $\square)$, 2-methylthio-L-ATP ( $\square$ ) and ATP (O). Each point is the mean of 8 observations on at least 8 different animals, and vertical lines indicate s.e.mean. 


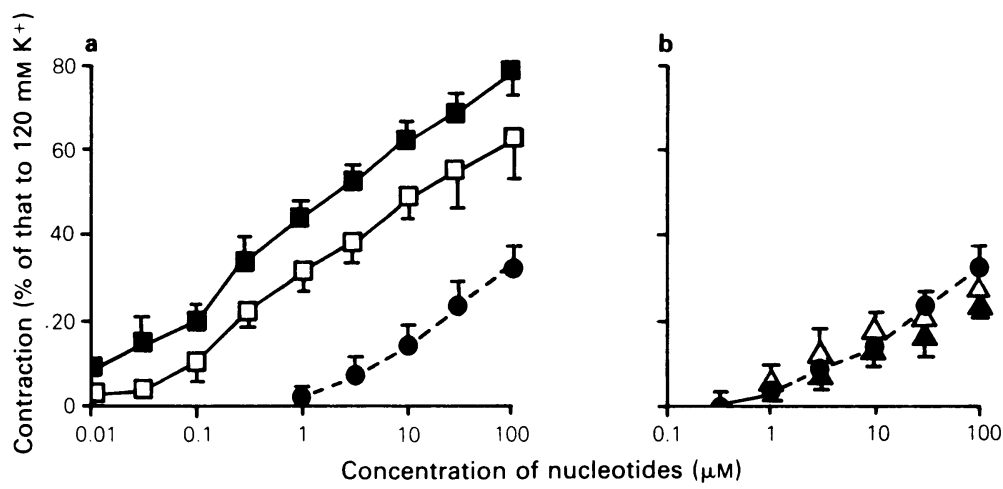

Figure 2 Concentration-response curves of the guinea-pig vas deferens to the contractions of (a) ATP( $(\bullet), \operatorname{Rp}-\mathrm{ATP} \beta S$

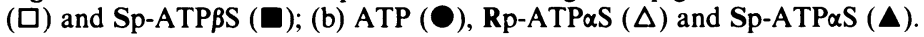

\section{Results}

ATP, L-ATP, 2-chloro-ATP, 2-chloro-L-ATP, 2methylthio-ATP, Rp-ATP $\alpha$ S, Sp-ATP $\alpha$ S, Rp-ATP $\beta S$ and Sp-ATPBS all contracted the guinea-pig vas deferens in a concentration-dependent manner, but 2 methylthio-L-ATP was active only at high concentrations (Figures 1 and 2).

ATP was more effective at inducing contractions than L-ATP (Figure 1a). 2-Chloro-ATP was more effective than its L-enantiomer, at every concentration, at causing contraction of the vas deferens. In addition, 2-chloro-ATP, at lower concentrations $(<100 \mu \mathrm{M})$ was more effective than ATP at contracting the vas deferens. However, at higher concentrations $(>300 \mu \mathrm{M})$ the nucleotides were equipotent. The Lenantiomer of 2-chloro-ATP was less potent than ATP at every concentration (Figure 1b). 2-Methylthio-ATP was more effective than 2-methylthio-L-ATP at every concentration. 2-Methylthio-ATP was virtually equipotent with ATP over the concentration range tested (Figure 1c).

Sp- and Rp-ATP $\beta S$ were more effective than ATP at every concentration, at contracting the vas deferens. In addition, the $\mathbf{R p}$ diastereoisomer of ATP $\beta S$ was more effective than the $\mathrm{Sp}$ diastereoisomer (Figure 2a). Both diastereoisomers of ATP $\alpha$ S were equipotent with ATP (Figure 2b).

\section{Discussion}

These results show that all of the ATP analogues can induce contraction of the guinea-pig vas deferens in a manner established for that of ATP itself (Hölck \& Marks, 1978; Westfall et al., 1978). These similarities, together with their structural relationship to ATP itself, suggest that these analogues all act at the $P_{2}$ purinoceptor, but in the absence of studies with reversible competitive ATP antagonists, this cannot be definitely proved. The results obtained with pairs of enantiomers of ATP show that 2-substitution gave little or no enhancement of the contractile response and this resembles their behaviour on the guinea-pig urinary bladder where 2-substitution does not lead to analogues more potent than ATP (Burnstock et al., 1983). On the other hand, the considerable stereoselectivity exhibited, especially towards the enantiomer of 2-methylthio-ATP is comparable to the high degree of stereoselectivity displayed by the inhibitory $\mathrm{P}_{2}$-purinoceptor on the guinea-pig taenia coli for this analogue (Burnstock et al., 1983).

In contrast, no stereoselectivity was observed for the $\mathbf{R p}$ and $\mathbf{S p}$ diastereoisomers of either of the phosphorothioate analogues of ATP. In addition, while neither diastereoisomer of $\mathrm{ATP} \alpha \mathrm{S}$ was more effective than ATP at inducing contraction of the vas deferens, each diastereoisomer of ATP $\beta S$ was much more effective than ATP, and this resembles the activity of these analogues on the guinea-pig bladder (Burnstock et al., 1984).

Our previous studies on the stereoselectivity of $\mathrm{P}_{2^{-}}$ purinoceptors led us to consider that a basis might exist for their subdivision (Burnstock et al., 1983; 1984), but the results of the present study appear to complicate the issue, since stereoselectivity of the excitatory $\mathrm{P}_{2}$-purinoceptor on the vas deferens seems to exhibit some of the characteristics of the inhibitory $\mathrm{P}_{2}$-purinoceptor on the guinea-pig taenia coli. Further studies with selective inhibitors of the inhibitory and excitatory responses are required to clarify this situation. 


\section{References}

ACTON, E.M., RYAN, K.J. \& GOODMAN, L. (1964). Synthesis of L-ribofuranose and L-adenosine. J. Am. Chem. Soc., 86, 5352-5354.

AMBACHE, N. \& ZAR, M.A. (1971). Evidence against adrenergic motor transmission in the guinea-pig vas deferens. $J$. Physiol., 216, 359-389.

BURNSTOCK, G. (1978). A basis for distinguishing two types of purinergic receptor. In Cell Membrane Receptors for Drugs and Hormones: A Multidisciplinary Approach. ed. Bolis, L. \& Straub, R.W. pp. 107-118. New York: Raven Press.

BURNSTOCK, G. (1981) (ed). Purinergic Receptors. Receptors and Recognition, Series B., Vol. 12. London: Chapman \& Hall.

BURNSTOCK, G., CUSACK, N.J., HILLS, J.M., MACKENZIE, I. \& MEGHJI, P. (1983). Studies on the stereoselectivity of the $\mathrm{P}_{2}$-purinoceptor. Br. J. Pharmac., 79, 907-913.

BURNSTOCK, G., CUSACK, N.J. \& MELDRUM, L.A. (1984). Effects of phosphorothioate analogues of ATP, ADP and AMP on guinea-pig taenia coli and urinary bladder. $\mathrm{Br}$. $J$. Pharmac., 83, 369-374.

CUSACK, N.J. \& HOURANI, S.M.O. (1981). Effects of Rp and Sp diastereoisomers of adenosine 5'-O-(1-thiodiphosphate) on human platelets. Br. J. Pharmac., 73, 409-412.

CUSACK, N.J. \& PLANKER, M. (1979). Relaxation of isolated taenia coli of guinea-pig by enantiomers of 2-azido analogues of adenosine and adenine nucleotides. $\mathrm{Br} . \mathrm{J}$. Pharmac., 67, 153-158.

CUSACK, N.J., HICKMAN, M.E. \& BORN, G.V.R. (1979). Effects of D- and L-enantiomers of adenosine, AMP and ADP and their 2-chloro and 2-azido-analogues on human platelets. Proc. R. Soc. B., 206, 139-144.

ECKSTEIN, F. \& GOODY, R.S. (1976). Synthesis and properties of diastereoisomers of adenosine $5^{\prime}$-O-(1-thiotriphosphate) and adenosine 5'O-(2-thiotriphosphate). Biochemistry, 15, 1685-1691.

FEDAN, J.S., HOGABOOM, G.K., O'DONNELL, J.P., COLBY, J. \& WESTFALL, D.P. (1981). Contributions by purines to the neurogenic response of the vas deferens of the guineapig. Eur. J. Pharmac., 69, 41-53.

FEDAN, J.S., HOGABOOM, G.K., WESTFALL, D.P. \& O'DONNELL, J.P. (1982). Comparison of contractions of the smooth muscle of the guinea-pig vas deferens induced by ATP and related nucleotides. Eur. J. Pharmac., 81, 193-204.

GOUGH, G.R., MAGUIRE, M.H. \& SATCHELL, D.G. (1973). Three new adenosine triphosphate analogs. Synthesis and effects on isolated gut. J. med. Chem., 16, 1188-1190.

HÖLCK, M.I. \& MARKS, B.H. (1978). Purine nucleoside and nucleotide interactions on normal and subsensitive alpha adrenoceptor responsiveness in guinea-pig vas deferens. J. Pharmac. exp. Ther., 205, 104-117.

HOLÝ, A. \& SORM, F. (1971). Nucleic acid components and their analogues CXL. Preparation of $5^{\prime}$-L-ribonucleotides, some of their derivatives and $2^{\prime}\left(3^{\prime}\right)-5^{\prime}-$ homooligo-L-ribonucleotides; coding properties of Lribonucleoside-containing oligonucleotides. Colln. Czech. Chem. Commun. (Engl. Edn.), 36, 3282-3299.

JAFFE, E.K. \& COHN, M. (1978). Divalent cation-dependant stereospecificity of adenosine 5'-O-(2-thiotriphosphate) in the hexokinase and pyruvate kinase reactions. J. biol. Chem., 253, 4823-4825.

MAGUIRE, M.H., NOBBS, D.M., EINSTEIN, R. \& MIDDLETON, J.C. (1971). 2-Alkylthioadenosines, specific coronary vasodilators. J. med. Chem., 14, 415-420.

MELDRUM, L.A. \& BURNSTOCK, G. (1983). Evidence that ATP acts as a cotransmitter with noradrenaline in sympathetic nerves supplying the guinea-pig vas deferens. Eur. J. Pharmac., 92, 161-163.

SATCHELL, D.G. \& MAGUIRE, M.H. (1982). Evidence for separate receptors for ATP and adenosine in the guineapig taenia coli. Eur. J. Pharmac., 81, 669-672.

SNEDDON, P., WESTFALL, D.P. \& FEDAN, J.S. (1982). Cotransmitters in the motor nerves of the guinea-pig vas deferens. Electrophysiological evidence. Science, 218, 693-695.

SWEDIN, G. (1971). Studies on neurotransmission mechanisms in the rat and guinea-pig vas deferens. Acta physiol. scand., Suppl., 369.

WESTFALL, D.P., STITZEL, R.E. \& ROWE, J.N. (1978). The postjunctional effects and neural release of purine compounds in the guinea-pig vas deferens. Eur. J. Pharmac., 50, $27-38$. 